\title{
Evaluation of Mobile Corporation Brand Business Performance based on Association Rules
}

\author{
Hongxia Guo ${ }^{1, a}$, Bin Pan $^{2, b^{*}}$ and Yong Liü ${ }^{2, c}$ \\ ${ }^{1}$ College of Information Science and Engineering, Chengdu University, Chengdu, China \\ ${ }^{2}$ College of Management Science, Chengdu University of Technology, Chengdu, China

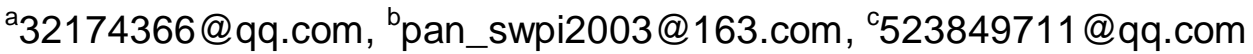

\begin{abstract}
Keywords: Association rules analysis; Mobile communication company; Tariff package; Operation performance evaluation
\end{abstract}

\begin{abstract}
In SQL Server 2010 environment, the association rules is used to analyze the data of mobile phone users bill, in order to find the correlation between the users consumption and the revenue of mobile communications company Sichuan branch. The performance contribution(PC) indicators of tariff package is calculated according to the Lift of each association rules, after comparing the itemsets of association rules with discount tariff packages, the paper analyzes whether the design of tariff package is reasonable, and could improve the operation performance.
\end{abstract}

\section{Introduction}

Economic value adding(EVA), balanced scorecard, comprehensive scorecard at past were widely used in the evaluation and analysis about enterprise performance $[1,2,3]$. In this paper, we introduces an entirely new method which draw related analysis theory of data mining into the company's brand business performance evaluation system, discusses the operation performance of tariff package scheme based on the data analysis result, and puts forward the improvement scheme according to the operation characteristic of Sichuan branch company of China Mobile Communication Corporation.

\section{Theory of Association Rule}

At present, most scholars use the clustering algorithm in data mining based on customer's actual using information to generate new tariff package scheme[4, 5]. The lift reflects the importance of an association rule, which can be used as the main parameter for calculating the business performance of the package. For association rule $\mathrm{R}: \mathrm{X}=>\mathrm{Y}$, Important $(\mathrm{X}=>\mathrm{Y})$ is used to represent the lift:

Impor $\tan t(X \Rightarrow Y)=\log ($ confidence $(X \Rightarrow Y) /$ confidence $(\bar{X} \Rightarrow Y))$

According to Eq. 1, it means:

Important $(X=>Y)>0$, the probability of $Y$ will become larger when the $X$ occurs,

Important $(X=>Y)=0, X$ and $Y$ have no association;

Important $(X=>Y)<0$, the probability of $Y$ will be smaller when $X$ occurs .

In our study, for the association rules $\mathrm{R}: \mathrm{X}^{*}=\mathrm{Y}^{*}, \mathrm{X}^{*} \in\left\{\mathrm{i}_{1}, \mathrm{i}_{2}, \mathrm{i}_{3}, \mathrm{i}_{4}, \mathrm{i}_{5}, \mathrm{i}_{6}, \mathrm{i}_{7}, \mathrm{i}_{8}\right\}, \mathrm{Y}^{*}=\mathrm{i}_{0}$, when Important $(R)>0$, if the company can take preferential measures for the business in $X$, the user's usage will improve, also the service quality and the performance will increase. If Important $(\mathrm{R})=0$ or Important $(\mathrm{R})<0$, the association rule $\mathrm{R}$ should be deleted.

\section{Itemsets and Index Selection}

We use association rules algorithm to analyze the correlation of business performance indexes, and get the final performance evaluation of the tariff package scheme[6].

The business indexes we selected can reflect the actual consumption of customers, and they are:

$\mathrm{i}_{0}$ :the monthly ARPU (Average Revenue PerUser);

$\mathrm{i}_{1}$ :the monthly GPRS traffic; 
$\mathrm{i}_{2}:$ the monthly local talk-time of dial-out;

$\mathrm{i}_{3}$ : the monthly talk-time long of toll call; $\mathrm{i}_{4}$ :the monthly number of the SMS;

$\mathrm{i}_{5}$ :the monthly talk-time of roaming calls;

$\mathrm{i}_{6}$ :the monthly talk-time of local call in own city;

$\mathrm{i}_{7}$ :the monthly call-time between different network;

$\mathrm{i}_{8}$ :the monthly call-time of the same network.

In these indexes, ARPU is the main evaluation index, it can explain each customer's contribution for company revenue, the higher the ARPU value, the higher the profit package. The Apriori algorithm can scan collectivity of all the indexes(I) and produces association rules of them. these association rules are represented as $\mathrm{R}: \mathrm{X}=>\mathrm{Y}, \mathrm{X} \in \mathrm{I}, \mathrm{Y} \in \mathrm{I}, \mathrm{X} \cap \mathrm{Y}=\varnothing[7,8]$. Then we should choose some of these association rules which meet the our requirements like $R: X^{*}=>Y^{*}, X^{*} \in\left\{i_{1}, i_{2}, i_{3}, i_{4}, i_{5}, i_{6}, i_{7}, i_{8}\right\}, Y^{*}=i_{0}$. The using of algorithm of association rules is to find the correlation between the ARPU and other indexes, then get the actual consumption status of the tariff packages, and get the operation performance evaluation finally.

After determining the index, we selected three kinds of brand "M-Zone", "Easy-own", "Go Tone" (each brand has 100000 service data) as the research sample. Considering the three brands contained different package types, and users of each type of package are identical, we use association rules to analysis sample data on the three brand seprately. The confidence and gain of association rules are two important metrics, and they are also two important parameters to evaluate the operation performance, for they represent the validity and importance of various rules respectively [9, 10]. According to the concept of association rules, the analysis model is established.

In order to study the business performance of each brand package, it is required that the items included in the association rules must belong to the preferential items included in the tariff package. The preferential services provided by "M-Zone" packages mainly include GPRS traffic, SMS, city calls, and Intranet calls, we set $S_{1}=\left\{i_{1}, i_{4}, i_{6}, i_{8}\right\}$. The preferential services provided by "Easy-own" packages mainly include local calls, city calls, Internet calls and Intranet calls, we set $S_{3}=\left\{i_{1}, i_{3}, i_{5}, i_{7}\right\}$. The preferential services provided by "Go Tone" packages include GPRS traffic, long distance calls, national roaming, and Internet calls, we set $S_{3}=\left\{i_{1}, i_{3}, i_{5}, i_{7}\right\}$. In all the association rules, we select the rules which $\mathrm{i}_{\mathrm{i}}(1 \leq \mathrm{i} \leq 8) \in \mathrm{S}$ and $\operatorname{Important}(\mathrm{X}=>\mathrm{Y}$ " $)>0$, finally get the needed association rules.

We set the tariff package performance contribution(PC) indicators to evaluate how many contributions the business portfolio included in the tariff packages have made to enhance the performance of business operations. The formula is as follows:

$$
P C=\sum \operatorname{Important}(\mathrm{X} \Rightarrow \mathrm{Y}), \quad \mathrm{X} \in\left\{\mathrm{i}_{1}, \mathrm{i}_{2}, \ldots, \mathrm{i}_{8}\right\}, \mathrm{Y}=\mathrm{i}_{0}
$$

tariff package performance contribution can be used as an indicator of the rationality and accuracy of a mobile package plan for a certain period of time. It has two important aspects: First, through the calculation of PC indicators for several consecutive periods, you can determine whether the customized service in the package meets the actual needs of users and provide the basis for the company to adjust the package tariff. In addition, historical data is used to calculate the correlation between PC indicators and corporate tariff package income to study the impact of business portfolio plans on package performance, and to redesign the best package plan.

\section{Data Analysis}

We take the SQL Server 2010 data services platform as our mining tools, and the business data has been collected into a database. Then we use the Apriori algorithm to process data, setting the minimum support degree Supmin=0.02 and the minimum confidence association rules Confmin $=0.4$, eventually get association rules of each package business data and obtained the Lift of corresponding association rules.

According to the Lift of the rules it can calculate the performance contribution of "M-Zone" package from Table 1. For example, $\mathrm{PC}_{1}=0.50+0.48+0.47+0.46+0.44+0.40+0.38=3.14$. Similarly it can 
calculate "Easy-own" package performance contribution $\mathrm{PC} 2=11.84$, "Go Tone" package performance contribution PC3=28.3.

Table 1 The Confidence and Lift of association rules

\begin{tabular}{ccc}
\hline Confidence & Lift & Association Rules \\
\hline 0.43 & 0.50 & $\left(\mathrm{i}_{4}<8, \mathrm{i}_{2}<125.19\right)=>$ ARPU $<33.39$ \\
0.41 & 0.48 & $\left(\mathrm{i}_{4}<8, \mathrm{i}_{7}<67.87\right)=>$ ARPU $<33.39$ \\
0.49 & 0.47 & $\left(285.96<\mathrm{i}_{2}<616.00,29.17<\mathrm{i}_{3}<113.82\right)=>$ ARPU $>=66.96$ \\
0.46 & 0.46 & $\left(29.17<\mathrm{i}_{3}<113.82,168.56<\mathrm{i}_{6}<408.27\right)=>$ ARPU $>=66.96$ \\
0.43 & 0.44 & $\left(285.96<\mathrm{i}_{2}<616.00,244.68<\mathrm{i}_{8}<572.60\right)=>$ ARPU $>=66.96$ \\
0.40 & 0.40 & $\left(174.58<\mathrm{i}_{7}<293.08,168.56<\mathrm{i}_{6}<408.26\right)=>$ ARPU $>=66.96$ \\
0.41 & 0.39 & $\left(29.17<\mathrm{i}_{3}<113.82, \mathrm{i}_{4}>=199\right)=>$ ARPU $>=66.96$ \\
\hline
\end{tabular}

According to the results it can be seen that the "M-Zone" package performance contribution value of PC1 relative to PC2 and PC3 is a lot lower. From association rules it can be seen that although "SMS(short message service) of M-Zone" monthly package has produced certain effect on improving ARPU, most users still use a lot of service that is not preferential in the package. For example, many users still use a lot of local call and toll call services and have to pay a lot for them, so the "M-Zone" package design is not reasonable. China Mobile communication company should make appropriate tariff adjustments in "M-Zone" packages to provide some preferential call services for users. "Easy-own" package performance contribution degree of PC2 was higher than that of PC1, but there are still room for improvement. From the consumption of "Easy-own" user, we can find what have most important influence on ARPU are local calls, calls of same network, and calls between different networks, and all preferential services provides basically meets the actual needs of most users, and its service has higher performance-price ratio than that of "M-Zone" packages. "Go Tone" PC3 package performance contribution degree is the highest of the three packages. The users of this package use a large number of toll calls which the China Mobile communication company provide preferential roaming calls, inter network call service packages. Although the users use a number of text messages and local calls, package services provides the main contribution function to the ARPU growth. "Go Tone" is a very successful package design of China Mobile Communication Corporation, its positioning is very accurate. In the future if the China Mobile communication company can master the appropriate balance between local calls and text messages, it can further enhance the class user's loyalty and the company operation performance.

\section{Conclusion}

By using association rules analysis in data mining, it could effectively get the relationship between the real consumption of users and the company business revenue. Comparing each project of the association rules and the preferential project of the package, it can analyze if the package design is reasonable, effective and meets the user's actual demand. And according to the articles of association rules mining gain degree calculation package performance contribution of this index, it provides an important parameter for evaluating the operation performance of communication service tariff package. In the future research, we could explore other more data mining method to evaluate the company's business activities, and finally establish an evaluation system of enterprise operation performance based on data mining method.

\section{Acknowledgements}

The authors wish to thank for the financial support of youth fund project of Sichuan province education office(No.10ZB088), youth key teachers training plan of Chengdu university of technology (No.10912-JXGG201413) and teaching reform project of Chengdu university(No.cdjgb2017111). 


\section{References}

[1] J.F. Liu: Dynamic association rules: Theory and applications. (MS. Zhejiang University, China, 2006), p.35. (In Chinese)

[2] L.L. Zhang, Q.L. Zhou, W.G. Tang, X.S. Li and Y. Shi: Chinese Journal of Management Science, Vol. 23 (2015) No.2, p. 154-161. (In Chinese)

[3] Z.G. Li, G. Ma: Data Warehouse and Data Mining Theory and Application (Higher Education Press, China 2008), p.146. (In Chinese)

[4] Michael J.A. Berry, Gordon Linoff: Data Mining Techniques. (Wiley Publishing, Inc., USA 2011), p.233.

[5] J.W. Han, M. Kamber and J. Pei: Data Mining: Concept and Techniques. (Morgan Kaufmann Publishers, USA 2011), p.136.

[6] W.S. Dai, H.B. Kuang and B.C. Xie: Statistical Research, Vol. 19 (2002) No.8, p.40-42. (In Chinese)

[7] T. Yi, B.W. Xu: Chinese Journal of Computers, Vol. 27 (2004) No. 5, p.703-710. (In Chinese)

[8] L. Jin: Research on the system of enterprise performance evaluation. (MS. Jiangsu University of Science and Technology, China, 2008), p.61. (In Chinese)

[9] S.W. Fan, F. Liu: East China Economic Management, Vol. 31 (2017) No.5, p.182-184. (In Chinese)

[10] M. Wang: Computer Knowledge and Technology, Vol. 7 (2011) No.16, p.3774-3776. (In Chinese) 